\title{
Padrão de desenvolvimento tecnológico dos municípios das Regióes Norte e Noroeste do Rio de Janeiro
}

\author{
Paulo Marcelo de Souza ${ }^{1}$ \\ Niraldo José Ponciano ${ }^{2}$ \\ Henrique Tomé da Costa Mata ${ }^{3}$ \\ Mônica do Nascimento Brito ${ }^{4}$ \\ Janete Golinski ${ }^{5}$
}

\begin{abstract}
Resumo: O objetivo deste estudo pesquisa foi caracterizar o grau de desenvolvimento tecnológico das Regiões Norte e Noroeste do estado do Rio de Janeiro. Foi empregada a técnica da análise fatorial, aplicada a um conjunto de variáveis relacionadas ao emprego de tecnologias. Constatou-se que há diferenças entre os níveis tecnológicos atingidos pelos municípios. Observou-se, ainda, uma mudança no padrão de desenvolvimento tecnológico a partir da década de 80, devido à redução na relação capital-trabalho, fenômeno provavelmente associado ao declínio da oferta de crédito rural e à elevação de seu custo.
\end{abstract}

Palavras-chaves: modernização, análise fatorial, tecnologia.

Abstract: The objective of the research was to characterize the degree of technological development of the North and Northwest regions of Rio de Janeiro state. Factor analyzes was used to characterize the degree of technological development. Differences between regions, concerning the technological development, were evidenced by research. A change in the pattern of the technological development, with reduction in relation to the capital-labour, was still observed since the 80s decade. This phenomenon is probably related to decrease of rural credit supply and elevation of its costs.

Key-words: modernization, factor analyzes, technology.

Classificação JEL: Q16, Q18.

${ }^{1}$ D. S. Economia Rural/UFV, Professor Associado à Universidade Estadual do Norte Fluminense (UENF). E-mail: pmsouza@uenf.br

${ }^{2}$ D. S. Economia Rural/UFV, Professor Associado à Universidade Estadual do Norte Fluminense (UENF). E-mail: ponciano@uenf.br

${ }^{3}$ D. S. Economia Aplicada/UFV, Professor Adjunto da Universidade Federal da Bahia (UFBA). E-mail: hnrmata@ufba.br

${ }^{4}$ Estudante de graduação em Agronomia na Universidade Estadual do Norte Fluminense(UENF).

${ }^{5}$ Mestranda em Produção Vegetal da Universidade Estadual do Norte Fluminense (UENF) 
Padrão de desenvolvimento tecnológico dos municípios das Regiões Norte e Noroeste do Rio de Janeiro

\section{Introdução}

A agricultura do estado do Rio de Janeiro tem sido marcada, historicamente, pela predominância de grandes propriedades, dedicadas ao cultivo da cana-de-açúcar e do café, bem como à criação de gado. De acordo com Marafon (2006), as grandes propriedades sempre ocuparam uma parcela considerável do estado, tendo desempenhado papel relevante nas exportações agrícolas do País. Entretanto, encerrados os ciclos fluminenses de exportação de café e açúcar, respectivamente nos períodos de 1900-1930 e de 1970-1980, a maioria das grandes propriedades dedicadas a esses produtos perdeu seu dinamismo, devido à crescente descapitalização associada à decadência das grandes lavouras comerciais.

A partir de meados da década de 70, foi adotado um conjunto de políticas voltadas à modernização da agricultura brasileira, como o crédito rural subsidiado, a política de preços mínimos, o seguro agrícola, os programas de pesquisa agronômica e extensão rural, os programas especiais de desenvolvimento, entre outras (BALSAN, 2006; BURIN, 2008). No estado do Rio de Janeiro, a atuação dessas políticas culminou na modernização de sua agricultura.

Segundo Monteiro e Mendonça (2007), esse estado experimentou, a partir das décadas de 60 e 70, um processo de modernização de sua agricultura, com base na monocultura, no uso intensivo de mecanização, de novas variedades, adubos sintéticos, defensivos e irrigação. Esse pacote tecnológico foi adotado por grandes e médios produtores, e também por parcela significativa dos agricultores familiares, arrendatários e meeiros.

Consideradas regiões de predomínio tradicional da atividade agropecuária, as Regiões Norte e Noroeste do estado do Rio de Janeiro certamente foram afetadas por esse conjunto de mudanças. Essas regiões são consideradas, respectivamente, espaços canavieiros e cafeeiros tradicionais do Brasil, que datam do século XVIII. Essa diferenciação das atividades econômicas, sobretudo as atividades agrícolas, foi determinada pelas diferenças de clima e relevo. De relevo plano, típico de baixada, e clima quente e úmido, a Região Norte do estado estruturou sua economia sobre a lavoura de cana-de-açúcar. Já o Noroeste fluminense, com relevo fortemente acidentado, não pôde fortalecer a lavoura da cana, mas se diferenciou em região produtora de gado de leite e café.

Ocupando 15.143,6 km², as Regiões Norte e Noroeste representam, conjuntamente, cerca de $35,3 \%$ da área total do estado. Compreendem os municípios de Campos dos Goytacazes, Cardoso Moreira, São Francisco de Itabapoana, São João da Barra, São Fidélis, Conceição de Macabu, Quissamã, Carapebus, Macaé (Região Norte), Porciúncula, Varre-Sai, Natividade, Itaperuna, Bom Jesus de Itabapoana, Itaperuna, Laje do Muriaé, Miracema, São 
José do Ubá, Santo Antônio de Pádua, Cambuci, Italva, Aperibé e Itaocara (Região Noroeste).

Ambas as regiões apresentam altos índices de pobreza rural e vivenciaram, nos últimos três séculos, uma sucessão de ciclos econômicos baseados no trinômio cana-café-pecuária, atualmente decadentes. Ainda que a proporção de pobres venha apresentando diminuição, a pobreza dos municípios do Norte e Noroeste fluminense atinge proporções semelhantes às regiões mais pobres do Nordeste brasileiro (RIO DE JANEIRO, 2008).

A Região Norte, de tradicional importância agrícola, tem vivenciado um processo de empobrecimento no campo, em parte devido às condições adversas do mercado de seu principal produto, a cana-de-açúcar (RIO DE JANEIRO, 2008). A produção de cana-de-açúcar na região da região retraiu-se nas últimas duas décadas, por efeito dos sucessivos planos econômicos, da extinção do IAA, da redução dos estímulos propiciados pelo Proálcool, bem como da baixa produtividade regional, fator de desvantagem num contexto de acirramento da competição com outras regiões (AZEVEDO, 2004).

Já a Região Noroeste, considerada a mais pobre do estado, sobrevive da cafeicultura, de uma pecuária pouco produtiva, de repasses dos governos federal e estadual, bem como de recursos da assistência social, a exemplo da aposentadoria rural (RIO DE JANEIRO, 2008). Como um dos agravantes, o cultivo do café, base da economia rural da região, vem sofrendo os efeitos da queda nos preços, iniciada ao final da década de 90, num cenário de estagnação do consumo mundial, oferta abundante e formação de estoques nos países importadores (SAES; NAKAZONE, 2002).

Diante dessas ocorrências, essas regiões vêm passando por um processo de esvaziamento do meio rural, devido ao declínio de suas agriculturas. Nessas regiões, observa-se um processo de diminuição gradativa da população rural, com conseqüente redução e envelhecimento da oferta de mão-de-obra, pela migração de jovens em busca de trabalho nas cidades beneficiadas pelos royalties do petróleo, de maior dinamismo (RIO DE JANEIRO, 2008).

Em síntese, as Regiões Norte e Noroeste, com altos índices de pobreza, têm sua economia baseada, em grande medida, na atividade agropecuária. A estagnação ou declínio dessa atividade tende a agravar os problemas dessas regiões, contribuindo para piorar seus baixos índices de desenvolvimento. Partindo do pressuposto de que o avanço tecnológico é fundamental para revitalizar a agricultura dessas regiões, conferindo-lhe maior competitividade, o presente trabalho busca analisar o processo de modernização tecnológica desse setor. Mais especificamente, pretende-se analisar a intensidade, a evolução e o comportamento do processo de modernização da agricultura dessas regiões e de seus municípios, durante as últimas três décadas. 
Padrão de desenvolvimento tecnológico dos municípios das Regiões Norte e Noroeste do Rio de Janeiro

\section{Objetivos}

O objetivo da pesquisa é fornecer evidências empíricas acerca do processo de modernização da agricultura nas Regiões Norte e Noroeste do Rio de Janeiro, bem como de seus municípios. Mais especificamente, busca-se verificar o padrão tecnológico adotado, a intensidade e a dinâmica da modernização, no período de 1970 a 1995.

\section{Metodologia}

A aferição da importância do processo de modernização nos municípios foi feita com o uso da análise fatorial, aplicada a um conjunto de variáveis relacionadas à utilização de tecnologias modernas. Esta medida possibilitou a descrição do processo de modernização nos municípios, permitindo ainda, por meio da análise de clusters, agrupá-los em classes distintas e mais ou menos homogêneas com respeito à importância deste processo.

\subsection{Análise fatorial}

Para estudar o processo de modernização da agricultura dos municípios, utilizou-se a análise fatorial. Esta técnica tem sido adotada como instrumental de análise em vários estudos sobre a modernização da agricultura, como em Souza e Khan (2001), Silva, Baptista e Fernandes (2003), Souza e Lima (2003), Ferreira Júnior, Baptista e Lima (2004), Silva e Fernandes (2005) e Vidal et al. (2007).

A análise fatorial refere-se a um conjunto de técnicas estatísticas, cujo objetivo comum é representar um grupo de variáveis em termos de um menor número de variáveis hipotéticas (KIM; MUELLER, 1978). De acordo com Schilderinck (1970), o método de análise fatorial consiste na tentativa de se determinar as relações quantitativas entre as variáveis, aferindo seus padrões de movimento, de modo a associar, àquelas com um padrão semelhante, o efeito de um fator causal subjacente e específico a estas variáveis. Essa técnica se baseia na suposição da existência de um número de fatores causais gerais, cuja presença dá origem às relações entre as variáveis observadas, de forma que, no total, o número de fatores é consideravelmente inferior ao número de variáveis. Isso porque muitas relações entre as variáveis são, em grande medida, devidas ao mesmo fator causal geral.

Dado um conjunto de $N$ observações de $n$ variáveis, para a realização da análise fatorial, estas variáveis devem ser inicialmente normalizadas, o que deve ser feito com o objetivo de possibilitar a comparação entre elas. A normalização consiste em expressar, em desvios-padrão, os desvios das observações originais em relação à sua média. Cada variável normalizada $z_{i}(i=1,2, \ldots, n)$ deve ser relacionada 
separadamente às variáveis hipotéticas ou fatores $f_{j}(j=1,2, \ldots, m),(m<n, N)$. Estas relações são lineares e assumem, no modelo básico de análise fatorial, a seguinte expressão analítica, conforme Harman (1960):

$$
z_{i}=a_{i 1} f_{1}+a_{i 2} f_{2}+\ldots+a_{i m} f_{m}+d_{i} u_{i} \quad(i=1,2, \ldots, n)
$$

em que cada uma das n variáveis é descrita, em termos lineares, como função dos $m$ fatores comuns $f_{j}(j=1,2, \ldots, m)$, aos quais se relacionam por meio das cargas fatoriais ou coeficientes de conexão $a_{i j}$, que indicam em que medida e direção as variáveis $z i$ estão relacionadas com o fator $f_{j}$; e de um fator único $u_{i}$, que responde pela variância remanescente.

Para saber se os fatores gerais causaram determinada relação entre as variâncias de $z_{i}$, é necessário que sua variância total $\left(\sigma_{i}^{2}\right)$ seja dividida em três componentes:

- a variância comum ou comunalidade, $h_{i}^{2}$, ou seja, que proporção da variância total de $z_{i}$ está associada com a variância das outras variáveis ou grupos de variáveis.

- a variância específica ou especificidade, $s_{i}^{2}$, isto é, a proporção da variância total que não mostra qualquer associação com a variância das outras variáveis; e

- o erro ou disturbância, $e_{i}^{2}$, que é a proporção da variância devida aos erros nas observações, ou a variáveis relevantes ao estudo, porém não consideradas no mesmo.

Os fatores únicos são sempre não correlacionados com os fatores comuns, e, se estes últimos não são correlacionados entre si, a variância total de $z_{i, \sigma i}{ }^{2}$, pode ser expressa por:

$$
\sigma_{i}^{2}=a_{i 1}^{2}+a_{i 2}^{2}+\ldots+a_{i m}^{2}+d_{i}^{2}
$$

em que os componentes $a_{i j}^{2}$ são denominados percentagem de conexão, e correspondem à proporção da variância total da variável normalizada $z_{i}$ que é explicada pelos respectivos fatores. Na expressão (2), o termo

$$
h_{i}^{2}=a_{i 1}^{2}+a_{i 2}^{2}+\ldots+a_{i m}^{2}
$$

equivale à comunalidade da variável $z_{i}$, ao passo que o termo $d_{i}^{2}$ corresponde à unicidade, ou seja, a contribuição do fator único, e indica a extensão em que os fatores comuns falham na explicação da variância total da variável.

A unicidade pode ser decomposta em duas partes: uma devida à seleção das variáveis, denominada especificidade $\left(s_{i}^{2}\right)$, e outra atribuída à não-confiabilidade das medidas, denominada erro $\left(e_{i}^{2}\right)$ :

$$
d_{i}^{2}=s_{i}^{2}+e_{i}^{2}
$$


Com essa decomposição, o modelo linear (4) pode ser escrito na forma:

$z_{i}=a_{i 1} f_{1}+a_{i 2} f_{2}+\ldots+a_{i m} f_{m}+b_{i} s_{i}+c_{i} e_{i} \quad(i=1,2, \ldots, n)$

em que $s_{i}$ e $e_{i}$ são os fatores específico e erro, respectivamente, e $b_{i}$ e $c_{i}$ são seus coeficientes.

\section{2. Índice Bruto de Desenvolvimento}

Uma vez obtidos os fatores e correspondentes escores fatoriais, a classificação dos municípios, segundo o grau de desenvolvimento tecnológico, foi realizada mediante o emprego do Índice Bruto de Desenvolvimento. Esse índice, utilizado por Melo e Parré (2007), é calculado com base na média ponderada dos escores fatoriais obtidos. Para um conjunto de $\mathrm{n}$ fatores e, conseqüentemente, $\mathrm{n}$ escores fatoriais, o índice bruto de modernização é obtido por:

$I B=\frac{\sum_{i=1}^{n} w_{i} F_{i}}{\sum_{i=1}^{n} w_{i}}$

em que:

$I B=$ Índice bruto de desenvolvimento

$W_{i}=$ proporção da variância explicada por cada fator

$F_{i}=$ escores fatoriais

\section{Variáveis e fonte de dados}

Dado o caráter multidimensional do conceito de modernização agrícola, a magnitude desse processo nos municípios, bem como sua evolução no período estudado, requer a consideração de um conjunto de variáveis capazes de captar a utilização das tecnologias modernas a ele associadas. Uma vez que não é o volume, mas a intensidade do uso das tecnologias modernas o aspecto de interesse, a maioria das variáveis são expressas em relação à mão-de-obra ocupada e em relação à área explorada.

De acordo com Hoffmann (1992), enquanto a área trabalhada (AT) equivale à soma das áreas ocupadas com lavouras permanentes e temporárias e com pastagens e matas plantadas, o conceito de área explorada $(A E)$ envolve, em adição às atividades admitidas na área trabalhada, as áreas cobertas por pastagens e matas naturais. Em relação à mão-de-obra ocupada, como as diferenças entre trabalhadores quanto a sexo, idade e tipo de dedicação têm implicações sobre o volume de trabalho disponibilizado, há que se adotar um procedimento de uniformização. Tal procedimento consistiu em utilizar o 
conceito de equivalente-homem-ano $(E H)$ que, por definição, corresponde à quantidade de trabalho de um homem adulto durante uma jornada de 300 dias ao ano. Para conversão dos dados originais acerca da força de trabalho empregada na agricultura dos municípios estudados, foram utilizados os fatores propostos por Kageyama e Graziano da Silva (1983), que são os seguintes:

- Homens maiores de 14 anos = 1,0 EH.

- Mulheres maiores de 14 anos:

- familiares =0,5 EH;

- empregados = 1,0 EH; e

- parceiros e outra condição $=0,66 E H$.

- Crianças menores de 14 anos:

- familiares =0,4 EH; e

- empregados e parceiros $=0,5 E H$.

Para descrever o processo de modernização da agricultura nos municípios das regiões Norte e Noroeste, no período de 1970 a 1995, as seguintes variáveis foram empregadas:

$X 1=$ Área explorada $/ E H$

$X 2=$ Área trabalhada $/ E H$

$X 3=$ Despesa com adubos corretivos $/ A E$

$X 4=$ Despesa com adubos e corretivos $/ E H$

$X 5=$ Despesa com defensivos $/ A E$

$X 6=$ Despesa com defensivos $/ E H$

$X 7=$ Despesa com sementes e mudas $/ A E$

$X 8=$ Despesa com sementes e mudas $/ E H$

$X 9=$ Despesa total $/ A E$

$X 10=$ Despesa total $/ E H$

$X 11=$ Número de arados de tração animal $/ A E$

$X 12=$ Número de arados tração animal / EH

$X 13=$ Número de arados tração mecânica $/ A E$

$X 14=$ Número de arados tração mecânica $/ E H$

$X 15=$ Número de máquinas para colheita $/ A E$

$X 16=$ Número de máquinas para colheita $/ E H$

$X 17=$ Número de silos para depósitos $/ A E$

$X 18=$ Número de silos para depósitos / $E H$

$X 19=$ Número de silos para forragem $/ A E$

$X 20=$ Número de silos para forragem $/ E H$

$X 21=$ Número de tratores $/ A E$

$X 22=$ Número de tratores $/ E H$

$X 23$ = Número de veículos tração animal $/ A E$

$X 24=$ Número de veículos tração animal / $E H$

X25 = Número de veículos tração mecânica / $A E$ 
$X 26$ = Número de veículos tração mecânica / EH

$X 27$ = Valor da produção $/ A E$

$X 28$ = Valor da produção / EH

$X 29=$ Valor dos financiamentos $/ A E$

$X 30=$ Valor dos financiamentos $/ E H$

$X 31=$ Valor dos financiamentos / valor da produção

$X 32=$ Valor dos investimentos $/ A E$

$X 33=$ Valor dos investimentos $/ E H$

Uma vez que o interesse da presente pesquisa recaiu sobre a dinâmica do processo de modernização, a análise fatorial foi conduzida agregando-se as observações feitas para os 33 indicadores, nos cinco anos considerados. Isso porque, se a análise fatorial fosse realizada para cada ano individualmente, os fatores obtidos num ano não seriam idênticos aos do ano seguinte, o que inviabilizaria qualquer tentativa de verificar o comportamento da modernização agrícola ao longo do período estudado. Desse modo, a análise incidiu sobre a matriz $M$, de dimensão 80 × 33, em que

$$
M=\left[\begin{array}{l}
M 1 \\
M 2 \\
M 3 \\
M 4 \\
M 5
\end{array}\right]
$$

sendo $M 1, M 2, M 3, M 4$ e $M 5$ as matrizes de ordem $16 \times 33$, referentes aos anos de 1970, 1975, 1980, 1985 e 1995, respectivamente, formadas pelos valores das 33 variáveis consideradas, observadas em cada uma das 16 localidades (Regiões Norte e Noroeste fluminense e seus municípios).

Todas as variáveis empregadas na análise foram calculadas a partir de informações disponíveis nos Censos Agropecuários da Fundação Instituto Brasileiro de Geografia e Estatística (FIBGE), dos anos de 1970, 1975, 1980, 1985 e 1995/96. Os valores monetários foram uniformizados e convertidos em Reais de 1994, utilizando-se o índice geral de preços-disponibilidade interna (base $1994=$ 100) da Fundação Getúlio Vargas (FGV). As análises foram realizadas no programa estatístico Statistical Package Software - SPSS 15.0.

É necessário, ainda, tecer algumas considerações a respeito das mudanças na distribuição geográfica das regiões consideradas, alterada em função das emancipações ocorridas ao longo do período estudado. Durante o período analisado, vários dos municípios que hoje constituem ambas as regiões ainda não existiam, ocupando ainda a condição de distritos dos municípios de consolidação mais antiga. Esse é o caso dos municípios: Varre-Sai, emancipado de Natividade, em 1993; de Cardoso Moreira, emancipado em 1988, formado a partir de antigos distritos 
de Campos dos Goytacazes; Italva, fundada em 1986, tendo sido desmembrada de Campos dos Goytacazes; Quissamã, que se emancipou de Macaé em 1989; Carapebus, outrora distrito de Macaé, emancipado em 1995; Aperibé, emancipado de Santo Antônio de Pádua, em 1992; São Francisco do Itabapoana, que pertencera ao município de São João da Barra, do qual se emancipou em 1995; e, São José de Ubá, fundada em 1997, após separar-se de Cambuci.

Para os municípios de Carapebus, São Francisco de Itabapoana e São José do Ubá, surgidos a partir de 1995, não havia quaisquer informações na fonte, já que o último Censo é o de 1995/96. Embora o Censo de 1995/96 já apresente informações sobre os municípios de Varre-Sai, Cardoso Moreira, Italva, Quissamã e Aperibé, optou-se por não incluí-los na análise, uma vez que essas informações estão disponíveis para um único ano. Neste caso, o procedimento adotado foi agregar esses municípios aos municípios dos quais se emanciparam. Com isso, assegurou-se a comparabilidade dos dados sobre os municípios de constituição mais antiga, cujos territórios foram mantidos como eram antes da cisão.

\section{Resultados}

\subsection{Fatores de modernização}

Para determinar se a análise fatorial é apropriada para o estudo dos dados empregados, Hair et al. (1995) sugeriram o uso de medidas que consideram toda a matriz de correlação entre as variáveis. Esse é o caso do teste de esfericidade de Bartlett, um teste estatístico para determinar a presença de correlações entre as variáveis que fornecem a probabilidade estatística de que a matriz de correlações tenha correlações significativas entre pelo menos algumas das variáveis. Esse teste foi realizado, e o valor obtido $(5.625,08)$ mostrou-se significativo a $1 \%$ de probabilidade, ou seja, permitiu rejeitar a hipótese nula de que a matriz de correlação é uma matriz identidade, isto é, de que as variáveis não são correlacionadas.

Outra medida para quantificar o grau de intercorrelações entre as variáveis e a adequação da análise fatorial ao conjunto de dados, sugerida pelo mesmo autor, é a medida de adequação da amostra. Essa medida pode assumir valores entre 0 e 1, atingindo a unidade quando cada variável é perfeitamente predita pelas demais. Neste estudo, o teste de Kaiser-Meyer-Olkim foi empregado como medida de adequação da amostra, e o valor obtido para o mesmo foi 0,58. Conforme a classificação fornecida por Hair et al. (1995), valores acima de 0,5 indicam que a amostra é adequada a esse tipo de análise, sendo esta a situação em que se encontram os dados empregados no estudo. Desse modo, ambos os testes realizados permitiram concluir que a amostra utilizada é adequada ao procedimento de análise, ou seja, ao emprego da análise fatorial.

A análise por meio do método dos componentes principais gerou seis fatores com raízes características maiores que 1, como pode ser observado na Tabela 1. 
Padrão de desenvolvimento tecnológico dos municípios

das Regiões Norte e Noroeste do Rio de Janeiro

Tabela 1. Fatores obtidos pelo método dos componentes principais

\begin{tabular}{cccc}
\hline Fator & $\begin{array}{c}\text { Raiz } \\
\text { Característica }\end{array}$ & $\begin{array}{c}\text { Variância Explicada } \\
\text { pelo Fator (\%) }\end{array}$ & $\begin{array}{c}\text { Variância } \\
\text { Acumulada (\%) }\end{array}$ \\
\hline 1 & 11,200 & 33,938 & 33,938 \\
2 & 9,406 & 28,503 & 62,441 \\
3 & 3,205 & 9,711 & 72,151 \\
4 & 2,559 & 7,754 & 79,905 \\
5 & 1,517 & 4,597 & 84,502 \\
6 & 1,172 & 3,552 & 88,054 \\
\hline
\end{tabular}

Fonte: Dados da pesquisa.

Uma vez que inexiste critério para definir qual o número de fatores principais que devem ser extraídos, optou-se pela caracterização do processo de modernização agrícola nos municípios considerados através dos quatro primeiros fatores, que, conjuntamente, explicam praticamente $80 \%$ da variância total das variáveis analisadas. Para facilitar a interpretação dos fatores, estes foram submetidos a uma rotação ortogonal pelo método varimax, sugerido por Kim e Mueller (1978). Com esse procedimento, a contribuição de cada fator para a variância total é alterada sem, contudo, modificar a contribuição conjunta deles. Como vantagem, os fatores obtidos após a rotação se encontram mais estreitamente relacionados a determinados grupos de variáveis, possibilitando melhor interpretação destes.

Na Tabela 2, são exibidos as cargas fatoriais, as comunalidades e o percentual da variância total dos indicadores que é explicado por cada fator, após a rotação. Feita a rotação, contribuição dos fatores F1, F2, F3 e F4 para explicação da variância total dos indicadores utilizados passa a ser de 33,44\%, 28,54\%, 9,13\% e $8,79 \%$, respectivamente, com contribuição conjunta de $79,9 \%$ para a explicação da variância total.

Para melhor interpretação, as cargas fatoriais com valor superior a 0,600 estão em negrito, evidenciando os indicadores mais fortemente associados a determinado fator. Pode-se constatar que o fator 1 está mais fortemente correlacionado às variáveis despesa com adubos corretivos/AE (X3), despesa com defensivos/AE (X5), despesa com sementes e mudas/AE (X7), despesa total/AE (X9), número de arados de tração animal/AE (X11), número de arados tração mecânica/AE (X13), número de silos para depósitos/AE (X17), número de silos para forragem/AE (X19), número de silos para forragem/EH (X20), número de tratores/AE (X21), número de veículos tração animal/AE (X23), número de veículos tração mecânica/AE (X25), valor da produção/AE (X27) e valor dos investimentos/AE (X32). Uma vez que a quase totalidade dessas variáveis refere-se à aplicação das tecnologias em relação à área explorada, esse fator será denominado intensidade do uso da terra. 
Já o segundo fator encontra-se mais fortemente correlacionado com as variáveis: área explorada/EH (X1), área trabalhada/EH (X2), despesa com adubos e corretivos/EH (X4), despesa com defensivos/EH (X6), despesa com sementes e mudas/EH (X8), despesa total/EH (X10), número de arados de tração mecânica/EH (X14), número de máquinas para colheita/EH (X16), número de tratores/EH (X22), número de veículos de tração mecânica/EH (X26) e valor da produção/EH (X28). Como essas variáveis refletem a relação entre a aplicação das tecnologias e a quantidade de mão-de-obra ocupada, esse fator será denominado relação capital-trabalho.

O fator 3 tem maior correlação com as variáveis: arados de tração animal/EH (12), número de silos para depósitos/EH (18) e número de veículos tração animal/EH (24). Embora esteja também relacionado à utilização de silos para depósito, por simplificação, esse fator será denominado emprego de força animal.

Finalmente, o fator 4 está associado às variáveis: valor dos financiamentos/AE (X29), valor dos financiamentos/EH (X30) e valor dos financiamentos/valor da produção (X31). A esse fator atribui-se a denominação de importância do financiamento, devido às variáveis a ele relacionadas.

Tabela 2. Cargas fatoriais após a rotação ortogonal e comunalidades obtidas na análise fatorial dos indicadores de modernização da agricultura nos municípios das Regiões

Norte e Noroeste do estado do Rio de Janeiro, de 1970 a 1995.

\begin{tabular}{|c|c|c|c|c|c|}
\hline \multirow{2}{*}{ Variável } & \multicolumn{4}{|c|}{ Fatores } & \multirow{2}{*}{ Comunalidades } \\
\hline & F1 & F2 & F3 & F4 & \\
\hline $\mathrm{X} 1$ & $-0,570$ & 0,651 & 0,002 & 0,083 & 0,755 \\
\hline $\mathrm{X} 2$ & $-0,210$ & 0,902 & 0,087 & $-0,125$ & 0,880 \\
\hline X3 & 0,772 & 0,202 & $-0,385$ & 0,009 & 0,785 \\
\hline$X 4$ & $-0,016$ & 0,879 & $-0,315$ & 0,089 & 0,880 \\
\hline X5 & 0,642 & $-0,019$ & 0,003 & $-0,004$ & 0,413 \\
\hline X6 & 0,110 & 0,912 & 0,116 & 0,048 & 0,860 \\
\hline $\mathrm{X} 7$ & 0,904 & 0,023 & $-0,175$ & $-0,051$ & 0,851 \\
\hline $\mathrm{X} 8$ & 0,294 & 0,681 & $-0,342$ & 0,021 & 0,668 \\
\hline X9 & 0,969 & 0,006 & $-0,021$ & $-0,079$ & 0,945 \\
\hline $\mathrm{X} 10$ & $-0,038$ & 0,976 & $-0,003$ & 0,009 & 0,954 \\
\hline X11 & 0,790 & $-0,179$ & 0,382 & $-0,083$ & 0,809 \\
\hline $\mathrm{X} 12$ & 0,044 & 0,171 & 0,888 & 0,017 & 0,820 \\
\hline $\mathrm{X} 13$ & 0,814 & 0,194 & $-0,120$ & $-0,176$ & 0,746 \\
\hline X14 & 0,080 & 0,950 & 0,115 & $-0,115$ & 0,936 \\
\hline $\mathrm{X} 15$ & 0,548 & 0,045 & 0,344 & $-0,223$ & 0,471 \\
\hline $\mathrm{X} 16$ & 0,026 & 0,814 & 0,387 & $-0,137$ & 0,831 \\
\hline $\mathrm{X} 17$ & 0,703 & $-0,187$ & 0,390 & 0,063 & 0,686 \\
\hline $\mathrm{X} 18$ & $-0,031$ & 0,024 & 0,615 & 0,392 & 0,534 \\
\hline
\end{tabular}


Padrão de desenvolvimento tecnológico dos municípios das Regiões Norte e Noroeste do Rio de Janeiro

Tabela 2. Continuação.

\begin{tabular}{|c|c|c|c|c|c|}
\hline \multirow{2}{*}{ Variável } & \multicolumn{4}{|c|}{ Fatores } & \multirow{2}{*}{ Comunalidades } \\
\hline & F1 & F2 & F3 & F4 & \\
\hline X19 & 0,917 & $-0,084$ & 0,148 & $-0,017$ & 0,869 \\
\hline $\mathrm{X} 20$ & 0,698 & 0,045 & 0,208 & 0,216 & 0,580 \\
\hline $\mathrm{X} 21$ & 0,908 & 0,128 & 0,081 & $-0,167$ & 0,875 \\
\hline $\mathrm{X} 22$ & 0,109 & 0,938 & 0,204 & $-0,102$ & 0,944 \\
\hline $\mathrm{X} 23$ & 0,902 & $-0,137$ & 0,248 & $-0,083$ & 0,900 \\
\hline $\mathrm{X} 24$ & 0,275 & 0,520 & 0,658 & 0,085 & 0,787 \\
\hline $\mathrm{X} 25$ & 0,884 & 0,163 & $-0,110$ & $-0,095$ & 0,829 \\
\hline $\mathrm{X} 26$ & 0,026 & 0,957 & 0,030 & $-0,051$ & 0,920 \\
\hline $\mathrm{X} 27$ & 0,941 & $-0,009$ & $-0,004$ & $-0,088$ & 0,893 \\
\hline $\mathrm{X} 28$ & $-0,046$ & 0,970 & 0,066 & $-0,005$ & 0,948 \\
\hline $\mathrm{X} 29$ & 0,167 & $-0,095$ & 0,073 & 0,917 & 0,883 \\
\hline X30 & $-0,218$ & 0,047 & $-0,015$ & 0,928 & 0,912 \\
\hline X31 & $-0,301$ & $-0,180$ & 0,273 & 0,748 & 0,758 \\
\hline X32 & 0,906 & 0,013 & $-0,153$ & 0,139 & 0,863 \\
\hline $\mathrm{X} 33$ & $-0,011$ & 0,545 & $-0,325$ & 0,426 & 0,584 \\
\hline \% da variância & 33,44 & 28,54 & 9,13 & 8,79 & \\
\hline
\end{tabular}

Fonte: Dados da pesquisa.

Uma vez determinados os fatores de modernização, a etapa seguinte consistiu em obter os escores fatoriais ${ }^{6}$, cujos valores encontram-se na Tabela A1, do anexo. De modo geral, pode-se concluir, a partir da análise das variações dos escores fatoriais nos distintos períodos, que a modernização agrícola tendeu a seguir um padrão semelhante nos diversos municípios das Regiões Norte e Noroeste fluminense. Como pode ser observado na Tabela 3, a década de 70 foi marcada por elevação dos valores dos fatores 1 e 2 em quase todos os municípios, com exceção: de Itaperuna e Laje do Muriaé, nos quais o Fator 1 exibiu pequeno declínio; dos municípios de São Fidélis e Bom Jesus do Itabapoana, em que o Fator 2 declinou na segundamente metade da década; e, de Campos, no qual ambos os fatores sofreram queda nesse mesmo período.

Já a primeira metade da década de 80 é marcada por declínio de ambos os fatores, com poucas exceções. Essa situação se reverte no período de 1985 a 1995, quando todos os municípios analisados voltam a exibir um crescimento do fator 1, em geral, acompanhado de um declínio no fator 2. Esse último fator exibe crescimento apenas em Natividade, São João da Barra e, sobretudo, no município de Campos, onde ele registra forte elevação.

${ }^{6}$ 6. Os escores fatoriais ( $\left.E F\right)$ são obtidos por (MONTEIRO e PINHEIRO, 2004): $E F=A^{\prime} \times R^{-1} \times Z^{\prime}$. Ou seja, são obtidos multiplicando-se a transposta da matriz de cargas fatoriais $(F)$, a matriz inversa da matriz de correlação $(R)$ e a transposta da matriz dos dados originais padronizados $(Z)$. 
Tabela 3. Variação dos escores fatoriais relativos aos fatores de modernização 1 (F1) e 2 (F2), no período de 1970 a 1995

\begin{tabular}{|c|c|c|c|c|c|}
\hline \multirow{2}{*}{ Município } & \multirow{2}{*}{ Fator } & \multicolumn{4}{|c|}{ Período } \\
\hline & & $70-75$ & $75-80$ & $80-85$ & $85-95$ \\
\hline \multirow{2}{*}{ B. J. Itabapoana } & $\mathrm{F} 1$ & 0,10 & 0,35 & $-0,20$ & 0,95 \\
\hline & $\mathrm{F} 2$ & 0,74 & $-0,21$ & $-0,06$ & $-0,40$ \\
\hline \multirow{2}{*}{ Cambuci } & F1 & 0,01 & 0,37 & $-0,14$ & 3,38 \\
\hline & $\mathrm{F} 2$ & 0,24 & 0,27 & $-0,01$ & $-0,55$ \\
\hline \multirow{2}{*}{ Campos } & F1 & 0,55 & $-0,04$ & $-0,30$ & 0,25 \\
\hline & $\mathrm{F} 2$ & 1,07 & $-0,54$ & $-0,19$ & 7,36 \\
\hline \multirow{2}{*}{ Conc. Macabu } & F1 & 0,41 & 0,10 & $-0,24$ & 4,60 \\
\hline & $\mathrm{F} 2$ & 1,35 & 0,33 & $-0,02$ & $-0,57$ \\
\hline \multirow{2}{*}{ Itaocara } & F1 & 0,16 & 0,20 & $-0,17$ & 1,92 \\
\hline & $\mathrm{F} 2$ & 0,16 & 0,06 & $-0,08$ & $-0,16$ \\
\hline \multirow{2}{*}{ Itaperuna } & F1 & $-0,07$ & 0,43 & $-0,09$ & 2,81 \\
\hline & $\mathrm{F} 2$ & 0,24 & 0,16 & 0,04 & $-0,33$ \\
\hline \multirow{2}{*}{ Laje do Muriaé } & F1 & 0,00 & 0,47 & $-0,19$ & 1,75 \\
\hline & $\mathrm{F} 2$ & 0,41 & 0,02 & $-0,08$ & $-0,11$ \\
\hline \multirow{2}{*}{ Macaé } & F1 & 0,22 & 0,25 & $-0,09$ & 0,76 \\
\hline & $\mathrm{F} 2$ & 1,07 & 0,34 & $-0,68$ & $-0,13$ \\
\hline \multirow{2}{*}{ Miracema } & F1 & 0,23 & 0,14 & $-0,15$ & 2,86 \\
\hline & $\mathrm{F} 2$ & 0,16 & 0,28 & $-0,18$ & $-0,11$ \\
\hline \multirow{2}{*}{ Natividade } & $\mathrm{F} 1$ & 0,11 & 0,72 & $-0,27$ & 1,97 \\
\hline & $\mathrm{F} 2$ & 0,22 & 0,80 & $-0,32$ & 0,36 \\
\hline \multirow{2}{*}{ Porciúncula } & $\mathrm{F} 1$ & 0,07 & 0,57 & $-0,20$ & 1,18 \\
\hline & $\mathrm{F} 2$ & 0,27 & 0,21 & 0,06 & $-0,41$ \\
\hline \multirow{2}{*}{ S. Ant. de Pádua } & F1 & 0,02 & 0,40 & $-0,26$ & 4,13 \\
\hline & $\mathrm{F} 2$ & 0,23 & 0,08 & $-0,12$ & $-0,01$ \\
\hline \multirow{2}{*}{ São Fidélis } & F1 & 0,20 & 0,01 & $-0,06$ & 0,82 \\
\hline & $\mathrm{F} 2$ & 0,13 & $-0,06$ & 0,03 & $-0,37$ \\
\hline \multirow{2}{*}{ S. João da Barra } & F1 & 0,20 & 0,26 & $-0,06$ & 0,75 \\
\hline & $\mathrm{F} 2$ & 0,28 & 0,13 & 0,02 & 0,21 \\
\hline
\end{tabular}

Fonte: Dados da pesquisa.

Com relação aos outros dois fatores, pode-se constatar, na Tabela 4, que ambos declinam na primeira metade da década de 70, o que se verifica em todos os municípios estudados. Na segunda metade dessa década, porém, observa-se um crescimento no fator 4 , que se dá em todos os municípios, acompanhado, de modo geral, de declínio ou estagnação do fator 3 .

Tal como observado em relação aos dois primeiros fatores, ocorre, na primeira metade da década de 80, redução dos fatores 3 e 4, com exceção apenas do município 
de Campos, onde há pequena elevação do fator 3. Em parte, essa tendência se reverte no período de 1985 a 1995, no qual se observa algum crescimento do fator 3 , na maior parte dos municípios, em alguns casos acompanhado também de crescimento no fator 4, como ocorre em Natividade e Santo Antônio de Pádua, principalmente. Nos municípios de São João da Barra e Bom Jesus do Itabapoana, ambos os fatores permanecem em declino neste período.

Tabela 4. Variação dos escores fatoriais relativos aos fatores de modernização 3 (F3) e 4 (F4), no período de 1970 a 1995

\begin{tabular}{|c|c|c|c|c|c|}
\hline \multirow{2}{*}{ Município } & \multirow{2}{*}{ Fator } & \multicolumn{4}{|c|}{ Período } \\
\hline & & $70-75$ & $75-80$ & $80-85$ & $85-95$ \\
\hline \multirow{2}{*}{ B. J. Itabapoana } & F3 & $-0,41$ & $-0,47$ & $-0,23$ & $-0,26$ \\
\hline & $\mathrm{F} 4$ & $-1,23$ & 2,57 & $-2,09$ & $-0,09$ \\
\hline \multirow{2}{*}{ Cambuci } & F3 & $-1,14$ & $-0,15$ & $-0,27$ & $-0,11$ \\
\hline & $\mathrm{F} 4$ & $-1,83$ & 2,78 & $-2,18$ & 0,40 \\
\hline \multirow{2}{*}{ Campos } & F3 & $-1,30$ & 0,62 & 0,28 & 3,77 \\
\hline & $\mathrm{F} 4$ & $-0,69$ & 2,36 & $-2,41$ & $-0,22$ \\
\hline \multirow{2}{*}{ Conc. Macabu } & F3 & $-1,02$ & 0,57 & $-0,54$ & $-0,97$ \\
\hline & $\mathrm{F} 4$ & $-0,61$ & 1,95 & $-1,17$ & 0,07 \\
\hline \multirow{2}{*}{ Itaocara } & F3 & $-1,01$ & 0,05 & $-0,56$ & 0,38 \\
\hline & $\mathrm{F} 4$ & $-0,53$ & 1,76 & $-1,06$ & $-0,39$ \\
\hline \multirow{2}{*}{ Itaperuna } & F3 & $-0,71$ & 0,04 & $-0,30$ & 0,07 \\
\hline & $\mathrm{F} 4$ & $-2,01$ & 2,96 & $-1,90$ & 0,04 \\
\hline \multirow{2}{*}{ Laje do Muriaé } & F3 & $-0,16$ & $-0,49$ & $-0,40$ & 2,25 \\
\hline & $\mathrm{F} 4$ & $-1,89$ & 2,89 & $-2,44$ & $-1,38$ \\
\hline \multirow{2}{*}{ Macaé } & F3 & $-0,74$ & $-0,16$ & $-0,11$ & 0,34 \\
\hline & $\mathrm{F} 4$ & $-0,33$ & 2,43 & $-1,17$ & $-1,13$ \\
\hline \multirow{2}{*}{ Miracema } & F3 & $-0,85$ & 0,37 & $-0,39$ & 1,04 \\
\hline & F4 & $-0,96$ & 2,42 & $-2,22$ & 0,02 \\
\hline \multirow{2}{*}{ Natividade } & F3 & $-1,05$ & $-0,93$ & $-0,24$ & 1,15 \\
\hline & $\mathrm{F} 4$ & $-1,31$ & 4,06 & $-3,18$ & 0,95 \\
\hline \multirow{2}{*}{ Porciúncula } & F3 & $-0,33$ & $-0,11$ & $-0,70$ & 0,14 \\
\hline & $\mathrm{F} 4$ & $-0,37$ & 3,32 & $-2,30$ & $-0,71$ \\
\hline \multirow{2}{*}{ S. Ant. de Pádua } & F3 & $-0,17$ & $-0,42$ & $-0,45$ & 1,72 \\
\hline & $\mathrm{F} 4$ & $-1,86$ & 2,36 & $-2,21$ & 1,26 \\
\hline \multirow{2}{*}{ São Fidélis } & F3 & $-0,87$ & $-0,27$ & $-0,10$ & 0,55 \\
\hline & $\mathrm{F} 4$ & $-0,98$ & 0,88 & $-0,64$ & $-0,40$ \\
\hline \multirow{2}{*}{ S. João da Barra } & F3 & $-0,41$ & $-0,24$ & $-0,02$ & $-0,49$ \\
\hline & $\mathrm{F} 4$ & $-0,71$ & 1,66 & $-1,25$ & $-0,48$ \\
\hline
\end{tabular}

Fonte: Dados da pesquisa. 
A partir da Figura 1, que exibe o comportamento dos fatores 1 e 2, em nível de mesorregiões, pode-se concluir que há diferenças significativas no desenvolvimento tecnológico entre as Regiões Norte e Noroeste. Nessa figura, pode-se observar que, em todo o período, a Região Norte tem apresentado relação capital-trabalho mais elevada do que a Região Noroeste. De qualquer modo, a Região Norte, a partir da segunda metade da década de 70, e também a Região Noroeste, a partir da década de 80 , vêm apresentando um processo de desenvolvimento tecnológico baseado no incremento na intensidade do uso da terra, com redução da relação capital-trabalho.

Figura 1. Comportamento dos fatores F1(intensidade da exploração da terra) e F2 (relação capital-trabalho) nas Regiões Norte e Noroeste do estado do Rio de Janeiro, 1970, 1975, 1980, 1985, 1990

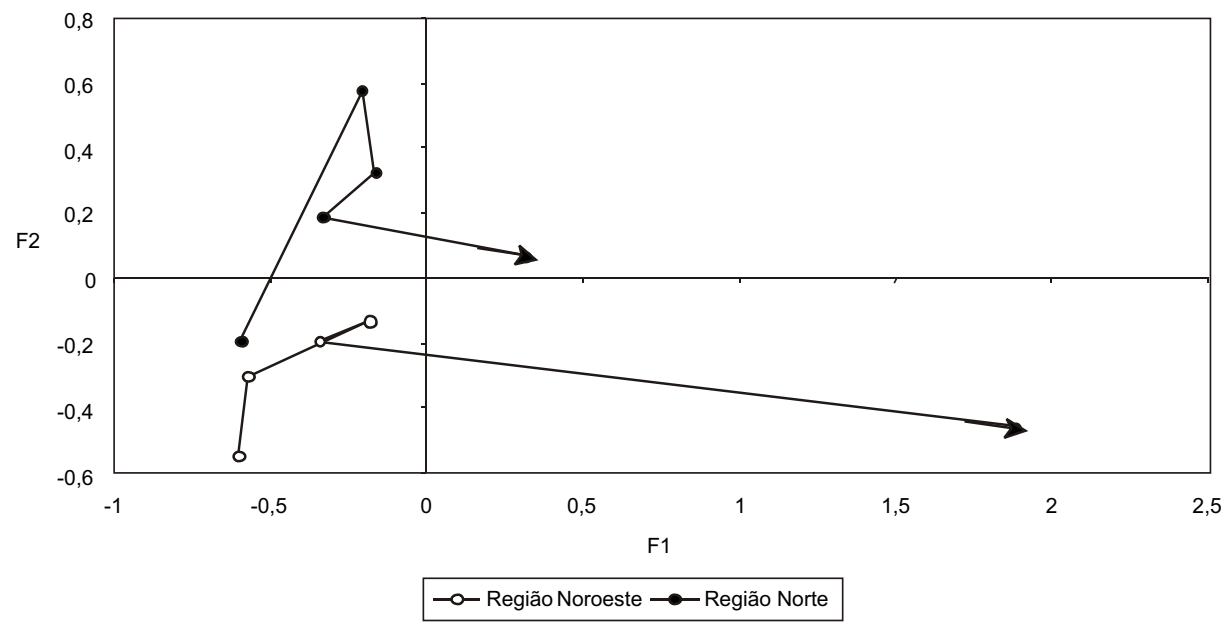

Fonte: Resultados da pesquisa.

A mudança do padrão de desenvolvimento tecnológico dessas regiões deve-se, provavelmente, à exaustão do modelo de incentivo à modernização agrícola que prevaleceu durante toda a década de $70^{7}$. A exaustão desse modelo, com a conseqüente redução do volume de crédito subsidiado, certamente afetou

\footnotetext{
7 7. A falência desse modelo ocorreu nos anos 80 , devido à crise macroeconômica desse momento, às mudanças estruturais e na conjuntura econômica, tudo isso evidenciando a necessidade de um novo paradigma de intervenção. Atuaram em favor dessa mudança de orientação os altos custos incorridos pelo Tesouro Nacional na condução da política, o desequilíbrio gerado entre a produção voltada para a exportação e a produção para o mercado interno, a alta instabilidade econômica no início dos anos 80, a ineficiência dos instrumentos então vigentes para contornar riscos e incertezas e o alcance da modernização tecnológica, eliminando a necessidade dos tradicionais mecanismos utilizados para induzi-la (BUAINAIN, 1997).
} 
os investimentos de longo prazo, nos quais se inserem os investimentos em máquinas e equipamentos, alterando o padrão de desenvolvimento tecnológico até então praticado, que se refletia na elevação da relação capital-trabalho.

A Figura 2 permite observar o comportamento dos fatores 3 e 4 , relativos ao emprego da força animal e ao uso de financiamentos, respectivamente. Neste caso, observa-se que, em todo o período, a Região Noroeste se destaca por apresentar valores sempre mais elevados do fator 3, relativo ao uso da tração animal.

Na primeira metade da década de 70 , ambas as regiões experimentam redução nos dois fatores, mas sobretudo no fator 3 . Na segunda metade dessa década, observa-se forte elevação do fator 4 , associado ao uso de financiamento, com poucas alterações no fator 3 . A partir de então, há forte declínio do fator 4 na primeira metade da década de 80 , refletindo a crise do modelo de financiamento até então vigente. No período de 1985 a 1995, mantém-se o declino do fator 4 na Região Norte, com pequena recuperação na Região Noroeste, em ambos os casos associado a uma elevação do fator 3, também de pouca importância.

Figura 2. Comportamentos dos fatores F3(força animal) e F4 (financiamentos) nas Regiões Norte e Noroeste do estado do Rio de Janeiro, 1970, 1975, 1980, 1985, 1990

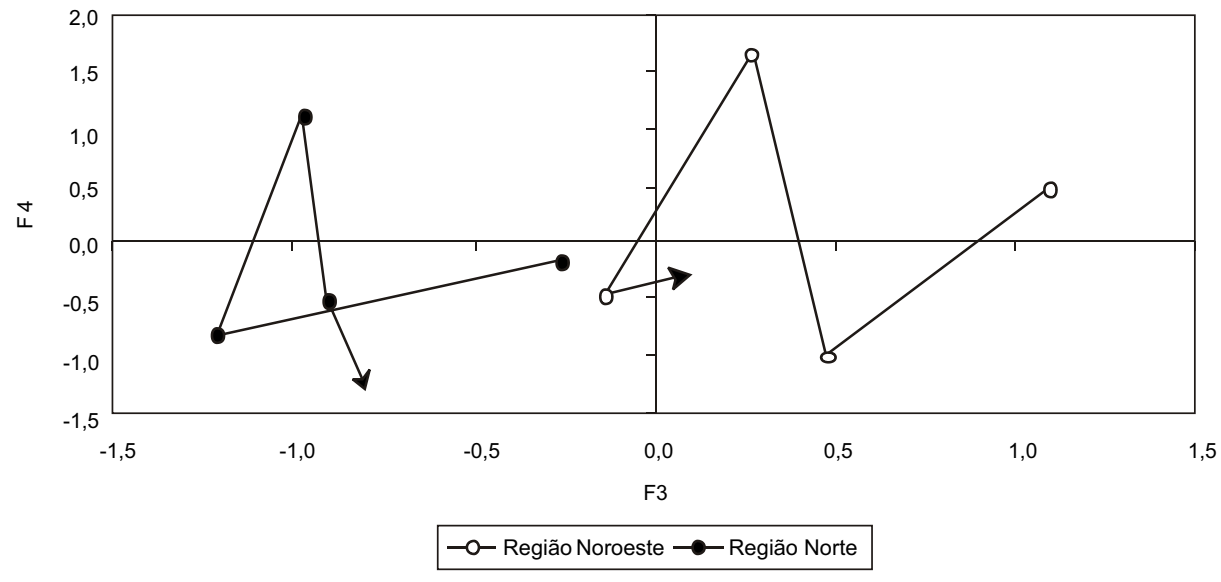

Fonte: Resultados da pesquisa.

Essas diferenças podem, de um lado, estar associadas ao perfil da estrutura fundiária dessas regiões e, de outro, ao tipo predominante de produção agrícola nelas desenvolvido. Como demonstrado por Souza, Ponciano e Mata (2007), a Região Norte tem uma estrutura fundiária mais concentrada, com predominância de propriedades maiores, nas quais a opção por um padrão de desenvolvimento tecnológico mais intensivo em mecanização implica na elevação da relação capital/trabalho e na elevação da produtividade da 
mão-de-obra. Ao contrário, na Região Noroeste, onde a importância das pequenas propriedades é maior, predomina um desenvolvimento tecnológico voltado para a elevação da intensidade de uso da terra e ao emprego da tração animal, justificada, ademais, pelo relevo mais acidentado dessa região. Além disso, a predominância do cultivo da cana-de-açúcar na Região Norte, e em particular no município de Campos dos Goytacazes, é, provavelmente, um fator que contribui para a elevação da relação capital-trabalho, dado as características de cultivo dessa cultura, desenvolvida em grandes áreas, nas quais a mecanização tende a substituir grande parte da mão-de-obra.

O índice bruto de desenvolvimento, cujos valores encontram-se na Tabela 5, possibilita uma síntese das transformações observadas. Nesta Tabela, pode-se constatar que, partindo de valores negativos no ano de 1970, este índice chega a 1995 com valores positivos na maior parte dos municípios. As exceções são Bom Jesus do Itabapoana, São Fidelis e São João da Barra que, ao final do período, exibem índices de desenvolvimento negativos. Essa evolução dos indicadores de modernização tecnológica mostra-se também mais favorável na Região Noroeste, visto que a Região Norte encerra o período com índice de desenvolvimento negativo.

Tabela 5. Índice bruto de desenvolvimento dos municípios das Regiões Norte e Noroeste fluminense

\begin{tabular}{lccccc}
\hline Região/Município & $\mathbf{1 9 7 0}$ & $\mathbf{1 9 7 5}$ & $\mathbf{1 9 8 0}$ & $\mathbf{1 9 8 5}$ & $\mathbf{1 9 9 5}$ \\
\hline Região Noroeste & $-0,271$ & $-0,402$ & 0,087 & $-0,279$ & 0,603 \\
B. J. Itabapoana & $-0,452$ & $-0,327$ & $-0,028$ & $-0,389$ & $-0,178$ \\
Itaperuna & $-0,167$ & $-0,411$ & 0,154 & $-0,112$ & 0,961 \\
Laje do Muriaé & $-0,154$ & $-0,233$ & 0,234 & $-0,186$ & 0,611 \\
Natividade & $-0,211$ & $-0,352$ & 0,573 & $-0,029$ & 1,157 \\
Porciúncula & $-0,491$ & $-0,443$ & 0,225 & $-0,169$ & 0,116 \\
Cambuci & $-0,194$ & $-0,436$ & 0,106 & $-0,225$ & 1,022 \\
Itaocara & $-0,296$ & $-0,348$ & $-0,042$ & $-0,322$ & 0,427 \\
Miracema & $-0,255$ & $-0,304$ & 0,163 & $-0,252$ & 1,029 \\
S. Ant. de Pádua & $-0,271$ & $-0,405$ & 0,002 & $-0,446$ & 1,613 \\
Região Norte & $-0,363$ & $-0,109$ & 0,058 & $-0,231$ & $-0,067$ \\
Campos & $-0,235$ & 0,153 & 0,274 & $-0,155$ & 2,983 \\
São Fidélis & $-0,363$ & $-0,441$ & $-0,395$ & $-0,491$ & $-0,258$ \\
S. João da Barra & $-0,572$ & $-0,513$ & $-0,206$ & $-0,364$ & $-0,085$ \\
Conc. Macabu & $-0,548$ & $-0,076$ & 0,361 & 0,061 & 1,680 \\
Macaé & $-0,458$ & $-0,102$ & 0,373 & $-0,051$ & 0,135 \\
\hline
\end{tabular}

Fonte: Dados da pesquisa. 
Ao se decompor as variações ocorridas no índice de desenvolvimento bruto entre os anos, é possível observar diferenças significativas quanto à evolução da modernização tecnológica no período, conforme Tabela 6. De início, constata-se que a primeira metade da década de 70 não apresenta tendência clara quanto ao comportamento do índice bruto de desenvolvimento que, de modo geral, mantém-se estagnado ou em declínio nos municípios da Região Noroeste, e se eleva nos municípios de Campos, Conceição de Macabu e Macaé, pertencentes à Região Norte. Já na segunda metade dessa década, todos os municípios experimentam elevação no índice bruto de desenvolvimento, certamente refletindo o efeito das políticas de modernização da agricultura, em sua fase áurea.

Tabela 6. Variação do índice bruto de desenvolvimento dos municípios das Regiões Norte e Noroeste fluminense

\begin{tabular}{lccccc}
\hline Região/Município & $\mathbf{7 0 - 7 5}$ & $\mathbf{7 5 - 8 0}$ & $\mathbf{8 0 - 8 5}$ & $\mathbf{8 5 - 9 5}$ & $\mathbf{7 0 - 9 5}$ \\
\hline Região Noroeste & $-0,131$ & 0,489 & $-0,366$ & 0,882 & 0,873 \\
B. J. Itabapoana & 0,125 & 0,299 & $-0,361$ & 0,211 & 0,274 \\
Itaperuna & $-0,245$ & 0,566 & $-0,266$ & 1,072 & 1,127 \\
Laje do Muriaé & $-0,079$ & 0,467 & $-0,420$ & 0,798 & 0,765 \\
Natividade & $-0,141$ & 0,925 & $-0,602$ & 1,186 & 1,368 \\
Porciúncula & 0,048 & 0,668 & $-0,394$ & 0,285 & 0,606 \\
Cambuci & $-0,242$ & 0,542 & $-0,331$ & 1,246 & 1,215 \\
Itaocara & $-0,051$ & 0,305 & $-0,279$ & 0,749 & 0,723 \\
Miracema & $-0,049$ & 0,467 & $-0,415$ & 1,281 & 1,284 \\
S. Ant. de Pádua & $-0,134$ & 0,407 & $-0,448$ & 2,059 & 1,884 \\
Região Norte & 0,254 & 0,167 & $-0,289$ & 0,164 & 0,296 \\
Campos & 0,388 & 0,121 & $-0,429$ & 3,138 & 3,218 \\
São Fidélis & $-0,078$ & 0,046 & $-0,096$ & 0,233 & 0,106 \\
S. João da Barra & 0,059 & 0,307 & $-0,158$ & 0,279 & 0,487 \\
Conc. Macabu & 0,472 & 0,438 & $-0,300$ & 1,618 & 2,228 \\
Macaé & 0,355 & 0,475 & $-0,424$ & 0,186 & 0,593 \\
\hline
\end{tabular}

Fonte: Dados da pesquisa.

Com o esgotamento dessas políticas, no início da década de 80, observa-se um declínio generalizado no uso das tecnologias abordadas, que se reflete na redução do índice bruto de desenvolvimento em todos os municípios. Essa situação se reverte no último período, quando se constata elevação no indicador de modernização tecnológica para todos os municípios, mesmo numa situação em que a oferta abundante de recursos financeiros subsidiados não mais existe. 
Considerando-se a diferença entre o início e o final da série analisada, constata-se que, sem exceções, os municípios de ambas as regiões experimentaram um incremento no uso das tecnologias abordadas e, conseqüentemente, no valor do índice bruto de desenvolvimento. Como pode ser constatado na Figura 3, o município de Campos, seguido dos municípios de Conceição de Macabu e Santo Antônio de Pádua foram os que apresentaram maior elevação do índice bruto de desenvolvimento. Em situação intermediária, encontram-se os municípios de Natividade, Miracema, Cambuci e Itaperuna, com os demais apresentando menor variação do índice bruto de desenvolvimento no período.

Figura 3. Variação do índice bruto de desenvolvimento dos municípios das Regiões Norte e Noroeste fluminense entre 1970 e 1995

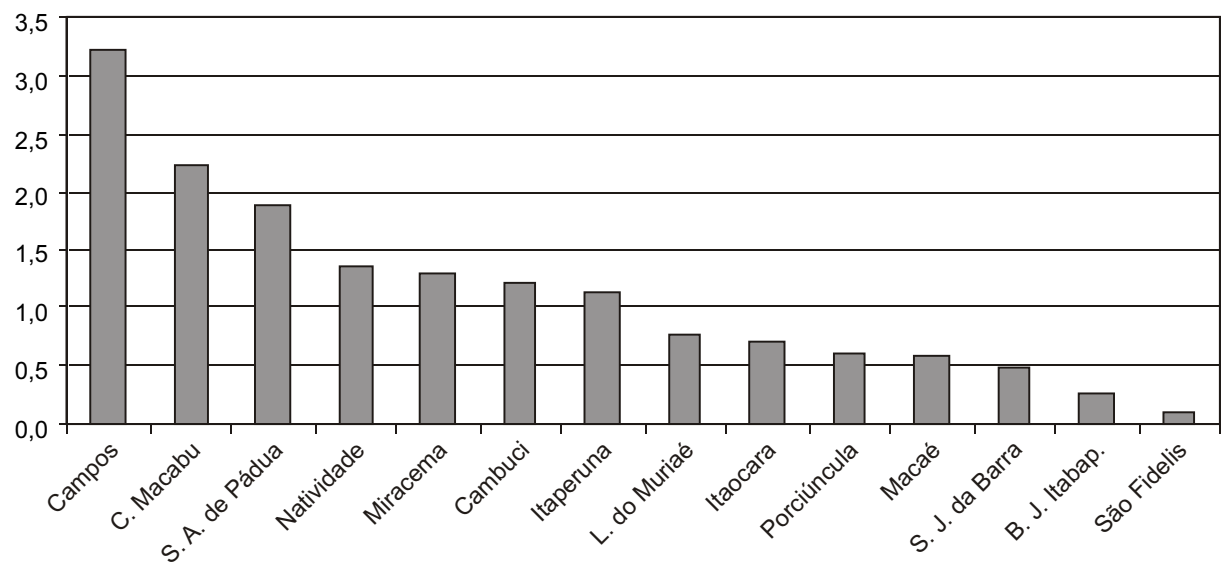

Fonte: Resultados da pesquisa.

Como reflexo do processo de modernização ocorrido, constata-se que, ao final do período considerado, o maior índice bruto de desenvolvimento encontra-se no município de Campos, destacando-se ainda os municípios de Conceição de Macabu e Santo Antônio de Pádua, conforme Figura 4. Em situação intermediária encontram-se os municípios de Natividade, Miracema, Cambuci e Itaperuna, ficando os demais em posição retardatária, com índices baixos ou até negativos.

Em nível de região, pode-se observar, na Figura 5, que a década de 70 foi marcada pelo crescimento dos índices de desenvolvimento tecnológico, com exceção de um pequeno declínio na primeira metade da década na Região Noroeste, mas ambas as regiões encerram essa década com índices semelhantes. A primeira metade da década de 80 é caracterizada pelo declínio do índice de desenvolvimento nas duas regiões, refletindo a crise do padrão de financiamento até então praticado. Esse resultado também foi observado para o conjunto da 
Padrão de desenvolvimento tecnológico dos municípios das Regiões Norte e Noroeste do Rio de Janeiro

agricultura brasileira que, segundo Martine (1989), reduziu o ritmo de incorporação tecnológica na primeira metade da década de 80 , como resultado da exaustão do padrão de financiamento até então vigente, bem como da retração do mercado, fruto da crise econômica desse período.

Figura 4. Índice bruto de desenvolvimento dos municípios das Regiões Norte e Noroeste fluminense em 1995

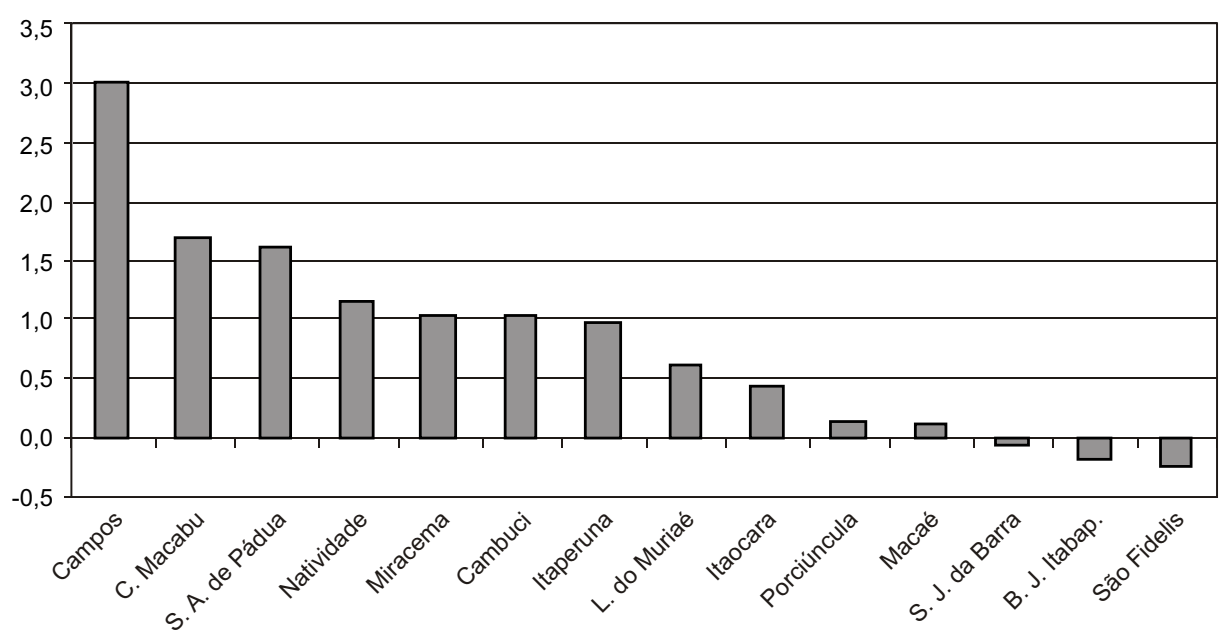

Fonte: Resultados da pesquisa.

Figura 5. Comportamento do índice bruto de desenvolvimento nas Regiões Norte e Noroeste fluminense, 1970 a 1995

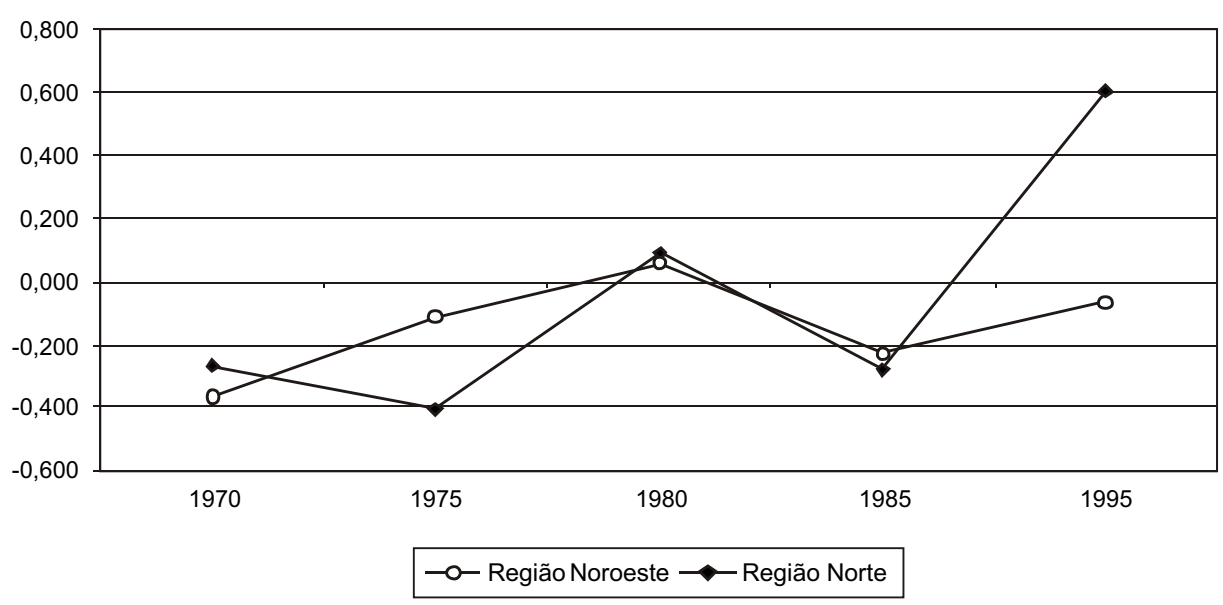

Fonte: Resultados da pesquisa. 
Entretanto, o índice bruto de desenvolvimento volta a se elevar entre $1985 \mathrm{e}$ 1995, o que se verifica em ambas as regiões. Há que se destacar, porém, que o crescimento desse índice é significativamente maior na Região Noroeste, enquanto na Região Norte o crescimento é insuficiente para situá-la sequer na posição que ocupava ao final da década de 70. Esse fato evidencia que a Região Norte, de estrutura fundiária mais concentrada e baseada na produção de cana-de-açúcar, parece ter sofrido mais fortemente a exaustão do modelo de financiamento da agricultura do que a Região Noroeste, cuja modernização prossegue a despeito da mudança ocorrida na política agrícola.

\section{Resumo e conclusões}

Os resultados evidenciaram que os melhores indicadores de modernização estão associados aos municípios de Campos dos Goytacazes, Conceição de Macabu e Santo Antônio de Pádua, que encerram o período analisado com os melhores índices brutos de desenvolvimento tecnológico. Além desses municípios, destacam-se ainda Natividade, Miracema, Cambuci e Itaperuna. Os piores indicadores são observados em Bom Jesus do Itabapoana, São Fidelis e São João da Barra que, ao final do período, apresentam índices brutos de desenvolvimento tecnológico negativos.

De modo geral, enquanto na Região Norte o processo de desenvolvimento tecnológico baseou-se na elevação da relação capital trabalho, na Região Noroeste, houve maior importância na elevação da intensidade do uso da terra e do uso da tração animal. A estrutura fundiária concentrada, o predomínio de áreas planas cultivadas com cana-de-açúcar na Região Norte, contrapostos à presença de menores propriedades e relevo acidentado na Região Noroeste, contribuem para explicar as diferenças no perfil tecnológico dessas regiões.

Constatou-se ainda que, embora o processo de desenvolvimento tecnológico tenha se processado em diferentes magnitudes entre os municípios, sua evolução seguiu um comportamento semelhante ao longo do tempo, caracterizada por maior avanço da relação capital-trabalho na década de 70, que dá lugar, nos anos seguintes, ao crescimento na intensidade do uso da terra.

A estagnação ou declínio da relação capital/trabalho, a partir da segunda metade da década de 80 deve-se, provavelmente, à queda na oferta de crédito rural e à elevação de seu custo, ao que se soma o efeito da retração ao do mercado, ocorridos na década de 1980. Não obstante, a redução na relação capital-trabalho, a análise evidenciou que o avanço tecnológico dos municípios prossegue, porém baseado crescentemente numa elevação da intensidade do uso da terra, e não mais no crescimento da relação capital-trabalho. 
966 - Padrão de desenvolvimento tecnológico dos municípios das Regiões Norte e Noroeste do Rio de Janeiro

\section{Referências Bibliográficas}

AZEVEDO, H. J. Uma análise da cadeia produtiva da cana-de-açúcar na região Norte Fluminense. In: PESSANHA, R. M., SILVA NETO, R. (Org.) Economia e desenvolvimento no Norte Fluminense: da cana de açúcar aos royalties do petróleo. Campos dos Goytacazes, RJ: WTC Editora, 2004. 364 p.

BALSAN, R. impactos decorrentes da modernização da agricultura brasileira. Campo-ferritório: revista de geografia agrária, v. 1, n. 2, p. 123-151, ago. 2006.

BURIN, J. C. As transformações ocorridas no espaço agrário brasileiro a partir do processo de modernização da agricultura. In: Simpósio Nacional de Educação "Ser Professor na Sociedade Contemporânea: Desafios e Contradições. Anais... Erechim-RS : EDIFAPES, 2008.

FERREIRA JÚNIOR, S.; BAPTISTA, A.J.M.S.; LIMA, J.E. A modernização agropecuária nas microrregiões do Estado de Minas Gerais. Brasília: SOBER. Revista de Economia e Sociologia Rural, v.42, n.1, 2004.

HAIR, J. F., Anderson, R. E., Tatham, R. L., \& Black, W. C. Multivariate Data Analysis: With Readings. Prentice Hall, New Jersey, 1995.

HARMAN, H. H. Modern Factor Analysis. University of Chicago Press, Chicago, 1960.

HOFFMANN, R. A dinâmica da modernização da agricultura em 157 microrregiões homogêneas do Brasil. Revista de Economia e Sociologia Rural, 30(4):271-90, 1992.

KAGEYAMA, A.; GRAZIANO DA SILVA, J. Produtividade e Emprego na Agricultura Brasileira in: BELLUZO, L.G.; COUTINHO, R. Desenvolvimento Capitalista no Brasil: Ensaios sobre a Crise. São Paulo: Brasiliense, 1983, v.2, p.192-222.

KIM, J. \& MUELLER, C. W. Introduction to Factor Analysis: What It is and How to Do It. Sage Publications, London, 1978.

MARAFON, G. J. (2006) Agricultura familiar, pluriatividade e turismo: reflexões a partir do território fluminense. Campo-Território: Revista de Geografia Agrária, Uberlândia, 1(1): 17-40.

MARTINE, G. Modernização e emprego rural no pós-guerra. In Congresso Brasileiro de Economia e Sociologia Rural, 33. Anais..., p. 162-89. Piracicaba, Sober, 1989.

MELO, C. O., PARRÉ, J. L. Índice de desenvolvimento rural dos municípios paranaenses: determinantes e hierarquização. Revista de Economia e Sociologia Rural, Rio de Janeiro, v. 45, no 02, p. 329-365, abr/jun 200 
MONTEIRO, D., MENDONÇA, M. M. de (2007) Agricultura e abastecimento no estado do Rio de Janeiro: críticas ao modelo hegemônico e questões a partir da agroecologia. Conferência Estadual de Segurança Alimentar e Nutricional do Rio de Janeiro. Disponível em: <www.aspta.org.br/programas-de-agriculturaurbana/parceiros-locais $>$.

MONTEIRO, V. P., PINHEIRO, J. C. V. Critério para implantação de tecnologias de suprimentos de água potável em municípios cearenses afetados pelo alto teor de sal. Revista de Economia e Sociologia Rural, 42(2): 365-387, 2004.

RIO DE JANEIRO, Secretaria de Agricultura, Pecuária, Pesca e Abastecimento. Avaliação Social. Projeto Rio Rural/BIRD: < http://www.agricultura.rj.gov.br/pdf/ AvaliacaoSocial.pdf $>$. Acesso em: dezembro de 2008.

SILVA, R.G.; BAPTISTA, A.J.M.S.; FERNANDES, E. A. Modernização agrícola na região norte: uma aplicação da estatística multivariada. Rio Verde: FESURV. RV Economia, ano 5, n 11, p.20-24, nov. 2003.

SAES, M. S. M., NAKAZONE, D. Estudo da competitividade de cadeias integradas no Brasil: impactos das zonas de livre comércio (cadeia café). Campinas: UNICAMP-IE-NEIT, 2002. 133p. (Nota Técnica Final)

SCHILDERINCK, J. H. F. Factor Analysis Applied to Developed and Developing Countries. Rotterdan University Press, Groningen,1970.

SILVA, R.G. e FERNANDES, E. A. Índice relativo de modernização agrícola na região Norte. Viçosa: UFV. Revista de Economia e Agronegócio, vol. 03, nํ01, p.29- 49, abril 2005.

SOUZA, P. M., LIMA, J. E. Intensidade e dinâmica da modernização agrícola no Brasil e nas unidades de federação. Rio de Janeiro: FGV. Revista Brasileira de Economia, v.57, n.4, p.795-824, 2003.

SOUZA, P. M., PONCIANO, N. J., MATA, H. T. C. Estrutura fundiária das regiões Norte e Noroeste do Estado do Rio de Janeiro: 1972 a 1998. Revista de Economia e Sociologia Rural, Rio de Janeiro, vol. 45, no 01, p. 071-091, jan/mar 2007.

SOUZA, R.F. e KHAN, A.S. Modernização da agricultura e hierarquização dos municípios maranhenses. Brasília: SOBER. Revista de Economia e Sociologia Rural, v.39, n.2, p.81-104, 2001.

VIDAL, M. B. ; SILVA, R. G. ; MENDONCA, M. S. ; LIMA, M. L. S. . Índice de modernização agrícola para os municípios do Acre. In: XVL Congresso Brasileiro de Economia e Sociologia rural. Anais.... Londrina: SOBER, 2007. 


\section{Anexo}

Tabela A1. Escores fatoriais das regiões Norte e Noroeste fluminense e municípios, $1970,1975,1980,1985$ e 1995

\begin{tabular}{|c|c|c|c|c|c|}
\hline \multirow{2}{*}{ Região/Muncípio } & \multirow{2}{*}{ Ano } & \multicolumn{4}{|c|}{ Fatores } \\
\hline & & F1 & $\overline{F 2}$ & F3 & $\mathbf{F 4}$ \\
\hline \multirow{5}{*}{ Região Noroeste } & 1970 & $-0,604$ & $-0,544$ & 1,092 & 0,471 \\
\hline & 1975 & $-0,571$ & $-0,302$ & 0,476 & $-0,994$ \\
\hline & 1980 & $-0,186$ & $-0,131$ & 0,266 & 1,648 \\
\hline & 1985 & $-0,348$ & $-0,194$ & $-0,136$ & $-0,443$ \\
\hline & 1995 & 1,886 & $-0,455$ & 0,088 & $-0,308$ \\
\hline \multirow{5}{*}{ B. J. Itabapoana } & 1970 & $-0,665$ & $-0,651$ & 0,321 & 0,205 \\
\hline & 1975 & $-0,563$ & 0,088 & $-0,087$ & $-1,026$ \\
\hline & 1980 & $-0,216$ & $-0,121$ & $-0,561$ & 1,546 \\
\hline & 1985 & $-0,411$ & $-0,185$ & $-0,789$ & $-0,548$ \\
\hline & 1995 & 0,534 & $-0,589$ & $-1,053$ & $-0,641$ \\
\hline \multirow{5}{*}{ Itaperuna } & 1970 & $-0,603$ & $-0,437$ & 1,271 & 0,879 \\
\hline & 1975 & $-0,674$ & $-0,194$ & 0,566 & $-1,132$ \\
\hline & 1980 & $-0,246$ & $-0,036$ & 0,603 & 1,829 \\
\hline & 1985 & $-0,332$ & 0,003 & 0,299 & $-0,071$ \\
\hline & 1995 & 2,480 & $-0,325$ & 0,368 & $-0,027$ \\
\hline \multirow{5}{*}{ Laje do Muriaé } & 1970 & $-0,594$ & $-0,556$ & 1,623 & 0,980 \\
\hline & 1975 & $-0,595$ & $-0,143$ & 1,465 & $-0,913$ \\
\hline & 1980 & $-0,126$ & $-0,119$ & 0,974 & 1,981 \\
\hline & 1985 & $-0,312$ & $-0,199$ & 0,579 & $-0,463$ \\
\hline & 1995 & 1,433 & $-0,304$ & 2,826 & $-1,843$ \\
\hline \multirow{5}{*}{ Natividade } & 1970 & $-0,628$ & $-0,366$ & 1,059 & 0,560 \\
\hline & 1975 & $-0,516$ & $-0,150$ & 0,006 & $-0,754$ \\
\hline & 1980 & 0,202 & 0,645 & $-0,919$ & 3,304 \\
\hline & 1985 & $-0,064$ & 0,325 & $-1,157$ & 0,128 \\
\hline & 1995 & 1,901 & 0,682 & $-0,011$ & 1,081 \\
\hline \multirow{5}{*}{ Porciúncula } & 1970 & $-0,683$ & $-0,541$ & 0,462 & $-0,585$ \\
\hline & 1975 & $-0,614$ & $-0,268$ & 0,129 & $-0,955$ \\
\hline & 1980 & $-0,042$ & $-0,056$ & 0,015 & 2,369 \\
\hline & 1985 & $-0,238$ & 0,005 & $-0,687$ & 0,066 \\
\hline & 1995 & 0,938 & $-0,403$ & $-0,543$ & $-0,646$ \\
\hline \multirow{5}{*}{ Cambuci } & 1970 & $-0,612$ & $-0,507$ & 1,401 & 0,759 \\
\hline & 1975 & $-0,604$ & $-0,269$ & 0,266 & $-1,068$ \\
\hline & 1980 & $-0,232$ & 0,005 & 0,116 & 1,710 \\
\hline & 1985 & $-0,370$ & $-0,001$ & $-0,154$ & $-0,473$ \\
\hline & 1995 & 3,006 & $-0,554$ & $-0,268$ & $-0,072$ \\
\hline
\end{tabular}




\begin{tabular}{|c|c|c|c|c|c|}
\hline \multirow{2}{*}{ Região/Muncípio } & \multirow{2}{*}{ Ano } & \multicolumn{4}{|c|}{ Fatores } \\
\hline & & F1 & F2 & F3 & F4 \\
\hline \multirow{5}{*}{ Itaocara } & 1970 & $-0,546$ & $-0,560$ & 1,405 & $-0,256$ \\
\hline & 1975 & $-0,389$ & $-0,404$ & 0,400 & $-0,783$ \\
\hline & 1980 & $-0,188$ & $-0,343$ & 0,447 & 0,979 \\
\hline & 1985 & $-0,354$ & $-0,425$ & $-0,113$ & $-0,081$ \\
\hline & 1995 & 1,570 & $-0,583$ & 0,269 & $-0,475$ \\
\hline \multirow{5}{*}{ Miracema } & 1970 & $-0,473$ & $-0,619$ & 1,112 & 0,338 \\
\hline & 1975 & $-0,246$ & $-0,456$ & 0,261 & $-0,617$ \\
\hline & 1980 & $-0,104$ & $-0,179$ & 0,628 & 1,806 \\
\hline & 1985 & $-0,253$ & $-0,356$ & 0,236 & $-0,414$ \\
\hline & 1995 & 2,609 & $-0,463$ & 1,276 & $-0,393$ \\
\hline \multirow{5}{*}{ S. Ant. de Pádua } & 1970 & $-0,586$ & $-0,696$ & 1,176 & 0,803 \\
\hline & 1975 & $-0,565$ & $-0,469$ & 1,006 & $-1,056$ \\
\hline & 1980 & $-0,164$ & $-0,393$ & 0,591 & 1,304 \\
\hline & 1985 & $-0,425$ & $-0,517$ & 0,137 & $-0,903$ \\
\hline & 1995 & 3,705 & $-0,530$ & 1,859 & 0,359 \\
\hline \multirow{5}{*}{ Região Norte } & 1970 & $-0,600$ & $-0,187$ & $-0,260$ & $-0,143$ \\
\hline & 1975 & $-0,209$ & 0,576 & $-1,213$ & $-0,806$ \\
\hline & 1980 & $-0,167$ & 0,324 & $-0,971$ & 1,120 \\
\hline & 1985 & $-0,333$ & 0,187 & $-0,907$ & $-0,501$ \\
\hline & 1995 & 0,315 & 0,067 & $-0,808$ & $-1,189$ \\
\hline \multirow{5}{*}{ Campos } & 1970 & $-0,472$ & 0,006 & $-0,359$ & 0,013 \\
\hline & 1975 & 0,078 & 1,074 & $-1,656$ & $-0,672$ \\
\hline & 1980 & 0,036 & 0,538 & $-1,039$ & 1,689 \\
\hline & 1985 & $-0,267$ & 0,345 & $-0,760$ & $-0,722$ \\
\hline & 1995 & $-0,022$ & 7,704 & 3,008 & $-0,937$ \\
\hline \multirow{5}{*}{ São Fidélis } & 1970 & $-0,701$ & $-0,524$ & 0,953 & 0,077 \\
\hline & 1975 & $-0,503$ & $-0,397$ & 0,088 & $-0,901$ \\
\hline & 1980 & $-0,496$ & $-0,459$ & $-0,183$ & $-0,024$ \\
\hline & 1985 & $-0,557$ & $-0,426$ & $-0,283$ & $-0,667$ \\
\hline & 1995 & 0,267 & $-0,791$ & 0,266 & $-1,065$ \\
\hline \multirow{5}{*}{ S. João da Barra } & 1970 & $-0,661$ & $-0,545$ & $-0,528$ & $-0,371$ \\
\hline & 1975 & $-0,459$ & $-0,265$ & $-0,941$ & $-1,079$ \\
\hline & 1980 & $-0,203$ & $-0,139$ & $-1,177$ & 0,576 \\
\hline & 1985 & $-0,262$ & $-0,123$ & $-1,193$ & $-0,674$ \\
\hline & 1995 & 0,486 & 0,088 & $-1,687$ & $-1,155$ \\
\hline \multirow{5}{*}{ Conc. Macabu } & 1970 & $-0,789$ & $-0,486$ & $-0,113$ & $-0,284$ \\
\hline & 1975 & $-0,375$ & 0,864 & $-1,133$ & $-0,896$ \\
\hline & 1980 & $-0,275$ & 1,190 & $-0,568$ & 1,056 \\
\hline & 1985 & $-0,517$ & 1,169 & $-1,109$ & $-0,118$ \\
\hline & 1995 & 4,083 & 0,598 & $-2,077$ & $-0,049$ \\
\hline \multirow{5}{*}{ Macaé } & 1970 & $-0,790$ & $-0,069$ & $-0,524$ & $-0,385$ \\
\hline & 1975 & $-0,566$ & 1,003 & $-1,268$ & $-0,716$ \\
\hline & 1980 & $-0,312$ & 1,339 & $-1,425$ & 1,710 \\
\hline & 1985 & $-0,405$ & 0,655 & $-1,532$ & 0,542 \\
\hline & 1995 & 0,359 & 0,522 & $-1,195$ & $-0,589$ \\
\hline
\end{tabular}

